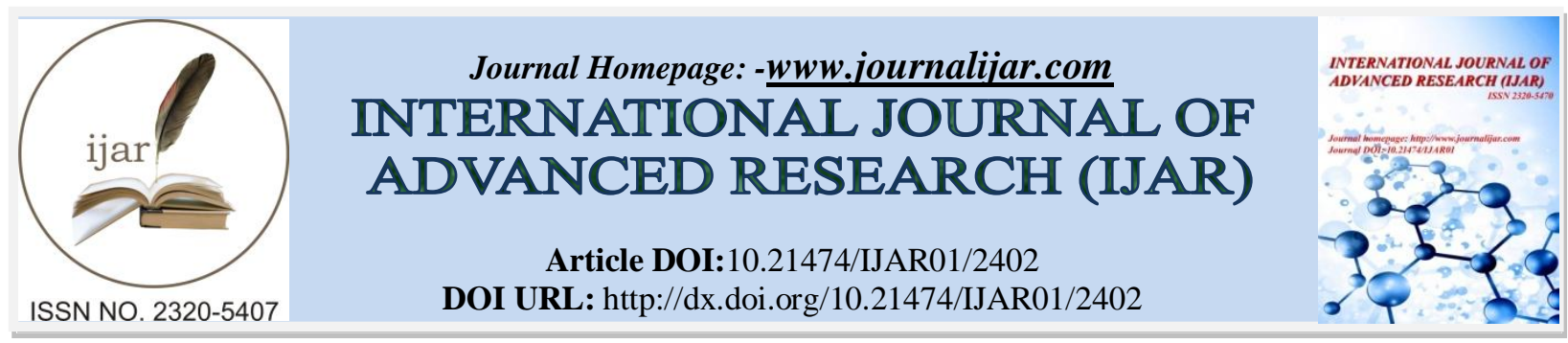

RESEARCH ARTICLE

VIRTUAL KEYBOARD.

\title{
SOCIAL DETERMINANTS OF HEALTH IN THE ELDERLY AND BIOETHICS.
}

\section{Sarmento. E. ${ }^{1}$, Rego. A. ${ }^{1}$ and ${ }^{*}$ Monteiro. M J ${ }^{2}$.}

1. Researcher, PhD., Universidade Católica Portuguesa, Instituto de Bioética, Rua Diogo Botelho, 1327, 4169-005 Porto, Portugal.

2. Researcher, PhD Professor, Universidade de Trás-os-Montes e Alto Douro, Escola Superior de Enfermagem, Vila Real, Portugal.

\section{Manuscript Info}

\section{Manuscript History}

Received: 19 October 2016

Final Accepted: 20 November 2016

Published: December 2016

Key words:-

Bioethics; Social Determinants of Health; Elderly

\section{Abstract}

The relationship between health and social determinants as a set of factors that influence the well-being, functional independence, quality of life and health of the elderly has as its agglutination the fact that it is the consequence of lifestyles, exposure to environmental factors and health care received, and is influenced by the capacity to maintain autonomy and independence. These social and health determinants can generate inequalities and vulnerabilities to be considered in the definition of health policies.

The objectives of this study are to identify the relationship between the social determinants and the health of the elderly, to analyze the bioethical challenges in the relationship between the different determinants, in the light of principles such as vulnerability and equity in the care of the elderly, and to mobilize sectors of society for this debate, in order to minimize health inequities. This study is transversal, exploratory, descriptive and analytical. The sample consisted of 339 participants aged $\geq 65$ years, of both sexes, who were able to express their consent and lived in rural parishes of Vila Real, in Portugal.

The descriptive analysis of the data revealed that there is an interdependence between social and health conditions. Therefore, it is important to conduct a survey and monitor non-clinical health determinants, promoting health policies that reduce inequities that generate inequality, for this is an ethical imperative.

We hope to contribute to a decision making aimed at achieving health gains by supporting those responsible at local, regional and national levels.

Copy Right, IJAR, 2016,. All rights reserved.

\section{Introduction:-}

Social determinants of health $(\mathrm{SDH})$ are defined as the characteristics within which life takes into account the conditions in which people live and work. They encompass social, economic, cultural, psychological and 
behavioral factors that influence the occurrence of health problems as well as the risk factors to which the population may be exposed (Geib, 2012).

Health policy can be based on objectives that represent the determinants of health, namely: (i) participation and influence in society; (ii) economic and social security; (iii) healthy professional life; (iv) medical services that can proactively promote health.

The causes of the emergence of diseases and inequities in health and the mechanisms by which conditions in the social context affect it can be modified by specific actions on the determinants such as retirement pension, education, occupation, family structure, availability of services, sanitation, exposure to diseases, social support networks, social discrimination and access to preventive health actions, which in a very direct way contribute to the perception of the state of health of the population, particularly the elderly.

Inequalities can be seen in the existing conditions, in the physical characteristics and in the quality of the natural environment in which people live, and the balance between rural and urban environments varies greatly (Santana and Costa, 2012). Today we have an unprecedented opportunity to improve health in the most vulnerable communities by addressing the causes of health and disease inequalities.

The pendular movement between the biomedical and sociological perspective is driven by a respectable advance in the study of the relations between the form of organization and the development of society and the health situation of its population. Thus, recognition of the inadequacy of health strategies that do not take into account social determinants may not have the necessary coverage to obtain the desired health gains. The creation of the Commission on Social Determinants of Health in 2005 by the World Health Organization (WHO) (Geib, 2012) has become an important milestone for the consolidation of this desired reality.

The WHO envisages even the cooperation between the biomedical/technological and social perspectives for health (Bonita et al., 2009) in a sustained and cooperative way, in order to obtain effective health gains at the lowest cost. Monitoring factors that positively or negatively influence the health status of a population enriches existing knowledge about the frequency and distribution of health determinants. It should therefore shape health policies and programs.

"The promotion of healthy aging concerns multiple sectors, including health, social security and labor, economic aspects, justice, rural and urban planning and development, housing, transport, new technologies, the culture and values that each society defends and that each citizen has as their own" (DGS, 2004a).

While it is true that individual, biological, genetic and psychological determinants contribute to the way we age and to the occurrence of illnesses throughout life, we must not forget that in many situations the decline in the functions associated with aging is closely related to external, behavioral, environmental and social factors, such as depression, loneliness and the isolation of many older people.

The impoverishment of social capital has been pointed out as a social determinant of health, which acts on the lifestyle, directly influencing the health conditions of the individual. The elderly, while impaired, tends to weaken the interaction and the affective contacts and to jeopardize the social support, which is based on a relation of reciprocity. These modifiable risk factors partially explain the epidemiological profile of noncommunicable diseases - cardiovascular diseases, diabetes, obesity, cancer, and respiratory diseases.

Health integrates the perspective of the course of life and recognizes the principles of diversity, dignity, independence, participation, responsibility, care and self-realization. It also recognizes, as can be seen in Figure 1, the choice of healthy lifestyles, including maintenance of physical activity and healthy eating; participation in social, health, economic, cultural, spiritual and civic activities in the physical and geographical environment (Botelho, 2005). 
Figure 1:- Determinants of health(Adapted from Commission for Social Determinants of Health, 2010)

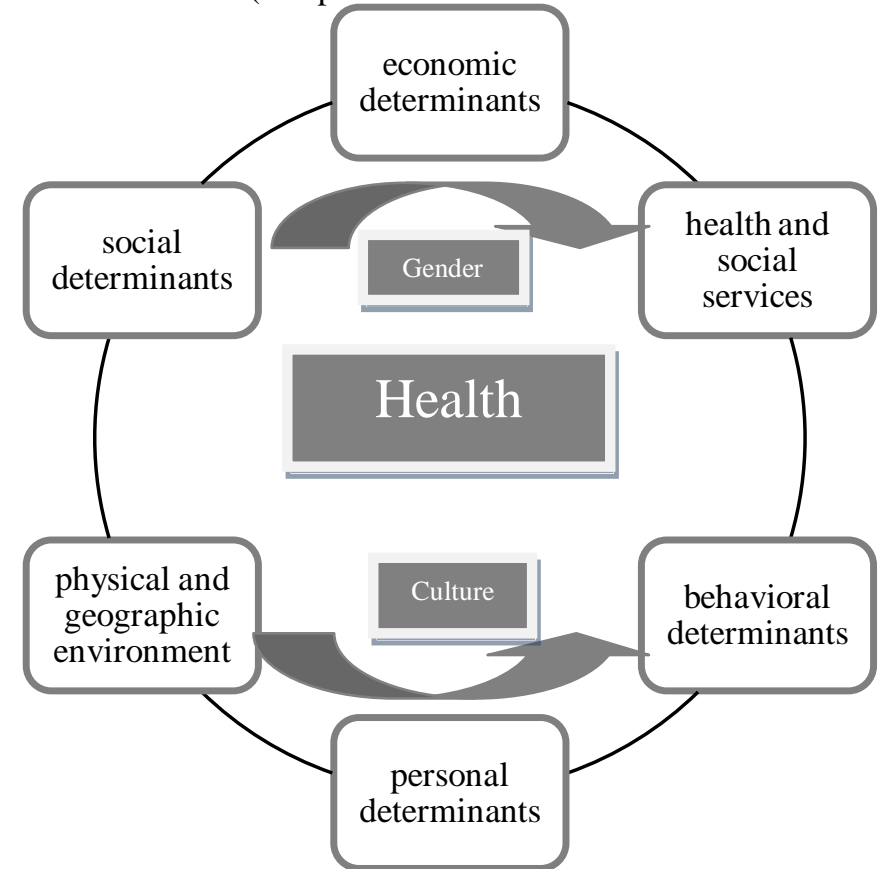

Culture has a decisive influence on the adoption of certain behaviors related to health (DGS, 2004b; WHO, 2005). Gender is another fundamental factor, through which one can consider the adequacy of certain interventions in the population. It is known that men and women age differently, considering the difference in lifestyles.

The factors that determine and influence the health status of a population are dynamic, systemic, and complex. Social demands for health and for health care providers are increasing. These aspects, coupled with improved social and health conditions, as well as technical and scientific development and greater health literacy, create new expectations and new development goals. Health systems are increasingly a central element of social protection and reduction of inequities, making a major contribution to cohesion, justice and social well-being (Giraldes, 1996).

Approximately two-thirds of premature deaths and one-third of the total adult morbidity may be linked to conditions or behaviors that began in youth. Thus, health maintenance requires a "lifelong" approach to behavior and lifestyle, beginning with gestation to protect the fetus and incorporation in childhood, keeping them until old age (World Bank, 2009).

\section{Material And Methods:-}

In this study, under the quantitative and exploratory, descriptive and analytical paradigm, the dependent variable was health perceived by the elderly living in rural parishes of a northern interior county of Portugal (Vila Real). Inclusion criteria was set as residency in one of the 15 rural parishes of the county, with $20 \%$ or more of the population aged $\geq 65$ years that accepted to participate in the study.

Using the Portuguese version (Guerreiro et al., 1994) of the Mini Mental State Examination (Folstein et al., 1975), the elderly with severe cognitive deterioration (total score of 15 points or less), as well as those who did not give consent to the questionnaire, or those whose health situation did not allow participation due to the impossibility of verbal/written communication, were excluded from participating in the study.

The sample consisted of 339 elderly participants of both genders of elderly people living in rural parishes.

Given the nature of the problem under study, we chose to use a questionnaire as the data collection instrument, which integrates variables of a quantitative nature that include: socio-demographic characterization, quality of life perception scale, Portuguese version of QV - WHOQOL-Bref and the Survey of Health, Ageing and Retirement in Europe (SHARE). 
All ethical procedures were ensured, regarding the authorization to carry out the study, and information was provided to the participants in order to obtain their informed consent.

The data was analyzed with the Statistical Package for the Social Science (SPSS), version 20.0 for Windows.

\section{Results:-}

Table 1 shows the sociodemographic characterization data of the sample regarding gender, age group, marital status, education level, main livelihood and type of housing.

Table 1:-Sociodemographic characteristics of the elderly living in the rural context of the municipality of Vila Real

\begin{tabular}{|l|l|c|c|}
\hline & & n & \% \\
\hline Gender & Female & 205 & 60,5 \\
& Male & 134 & 39,5 \\
\hline Age group & $65-70$ & 133 & 39,2 \\
& $71-76$ & 65 & 19,2 \\
& $77-82$ & 79 & 23,3 \\
& $83-88$ & 41 & 12,1 \\
& $\geq 89$ & 21 & 6,2 \\
\hline Marital status & Not married & 23 & 6,8 \\
& Married with registration & 188 & 55,5 \\
& Unregistered marriage - de facto union & 4 & 1,2 \\
& Divorced/Separated & 7 & 2,1 \\
& Widower & 117 & 34,5 \\
\hline Education level & No education & 91 & 26,8 \\
& Elementary School (1st cycle) & 204 & 60,2 \\
& Elementary School (2nd cycle) & 16 & 4,7 \\
& Elementary School (3rd cycle) & 13 & 3,8 \\
& Secondary School & 10 & 2,9 \\
& Higher Education & 5 & 1,5 \\
\hline Main livelihood & Working income & 18 & 5,3 \\
& In charge of family & 8 & 2,4 \\
& Pension reform & 308 & 90,9 \\
& Income (property/company) & 2 & 0,6 \\
& Social support (other) & 2 & 0,6 \\
& Other situations & 1 & 0,3 \\
\hline Type of housing & Own & 291 & 85.8 \\
& Rented & 26 & 7,7 \\
& Loaned & 13 & 3,8 \\
& Other & 9 & 2,7 \\
\hline
\end{tabular}

Sociodemographic variables allow more than one occurrence for each individual. In this way, the results related to these variables were considered for the target population of the study, namely in what concerns the sample. As for the main sociodemographic characteristics of the individuals, $60.5 \%$ of the sample is female, $39.2 \%$ between 65 and 70 years old, followed closely by $23.3 \%$ of the elderly who are between 77 and 82 years. As for marital status, $55.5 \%$ are married with registration and $34.5 \%$ are widowers. It is also relevant to mention that 93 of the widowers are women and 24 are men.

The majority of the elderly (87.0\%) have a low level of education, with $26.8 \%$ having no academic degree and $60.2 \%$, completed only the first cycle of elementary education. In this sample, only one male and four female subjects had completed higher education. Retirement pensions account for $90.9 \%$ of the main livelihoods, with $85.8 \%$ of the elderly owners of their housing. Of these, the typology of the autonomous house is more frequent (71.1\%), compared with $26.3 \%$ residing in a dwelling that nevertheless presents, in a global way, precarious housing conditions. 
We present below the results related to the multidimensional evaluation of the adaptation to the aging process, starting with Table 2, which presents the distribution of the answers regarding the self-perception of the elderly about their state of mind.

Table 2:-State of mind referred by the elderly

\begin{tabular}{|c|c|c|}
\hline & $\mathbf{n}$ & $\%$ \\
\hline I have no trouble walking & 185 & 54,6 \\
\hline I have some trouble walking & 145 & 42,8 \\
\hline I have to stay in bed & 9 & 2,7 \\
\hline I have no problem taking care of myself & 242 & 71,4 \\
\hline I have some problems washing up or getting dressed & 74 & 21,8 \\
\hline I am unable to wash or dress myself & 23 & 6,8 \\
\hline I have no problem performing my usual activities & 181 & 53,4 \\
\hline I have some problems performing my usual activities & 127 & 37,5 \\
\hline I am unable to perform my usual activities & 31 & 9,1 \\
\hline I have no pain or discomfort & 108 & 31,9 \\
\hline I have moderate pain or discomfort & 208 & 61,4 \\
\hline I have extreme pain or discomfort & 23 & 6,8 \\
\hline I am not anxious or depressed & 192 & 56,6 \\
\hline I am moderately anxious or depressed & 128 & 37,8 \\
\hline I am extremely anxious or depressed & 19 & 5,6 \\
\hline
\end{tabular}

Regarding the studied population, $54.6 \%$ reported no problem in mobility, although $42.8 \%$ mentioned it; $71.4 \%$ did not have any difficulty in taking care of themselves and $53.4 \%$ performed, without constraints, their usual activities. It is noteworthy that $37.5 \%$ have some limitations in carrying out their usual activities and that $61.4 \%$ reported having moderate pain or malaise. Although $56.6 \%$ of study participants did not feel anxious or depressed, we consider relevant to mention that $37.8 \%$ of the respondents reported feeling moderately anxious or depressed.

Tables 3, 4 and 5 intend to summarize the health expenses. It is important and relevant for the management of (scarce) health resources to better understand and comprehend the reality of health in the context of the aging Portuguese population, not neglecting its differentiation and the regional and local particularities. Over the years, considering organic decreases and decompensation of physiological balance (which lead to significant changes in body shape and composition and greater susceptibility to certain pathologies), such as changes in structure and functional losses, contributes to better management resources.

Table 3 presents data on health problems reported by the elderly in the last six months before the questionnaire was applied.

Table 3:- Health issues referred by the elderly in the last six months.

\begin{tabular}{|c|c|c|c|c|}
\hline & \multicolumn{2}{|c|}{ Yes } & \multicolumn{2}{|c|}{ No } \\
\hline & $\mathbf{n}$ & $\%$ & $\mathbf{n}$ & $\%$ \\
\hline Back, knee, hip or other joint pain & 255 & 75,2 & 84 & 24,8 \\
\hline Heart problems and chest pains during physical exercise & 93 & 27,4 & 246 & 72,6 \\
\hline Difficulty breathing & 90 & 26,5 & 249 & 73,5 \\
\hline Persistent cough & 60 & 17,7 & 279 & 82,3 \\
\hline Swollen legs in edema & 141 & 41,6 & 198 & 58,4 \\
\hline Trouble sleeping & 158 & 46,6 & 181 & 53,4 \\
\hline Falling & 90 & 26,5 & 249 & 73,5 \\
\hline Fear of falling & 143 & 42,2 & 196 & 57,8 \\
\hline Dizziness or fainting & 81 & 23,9 & 258 & 76,1 \\
\hline Stomach or bowel problems & 102 & 30,1 & 237 & 69,9 \\
\hline Incontinence or involuntary loss of urine & 79 & 23,3 & 260 & 76,7 \\
\hline Fatigue & 166 & 49,0 & 173 & 51,0 \\
\hline None & 46 & 13,6 & 293 & 86,4 \\
\hline Other symptoms that were not mentioned & 25 & 7,4 & 314 & 92,6 \\
\hline
\end{tabular}


When questioned about the health problems that had bothered them the most in the past six months, by the time the questionnaire was applied, the participants found as most relevant: back pain, knees, hips or other joint (75.2\%), fatigue (49.0\%),trouble sleeping (46.6\%), fear of falling (42.2\%) and swollen legs and edema $(41.6 \%)$. The perception of the existing model for elderly care is not adequate to the satisfaction of their health needs. Despite more frequent use of health care, their complaints continue to persist. We verified that the elderly consume more and more resources of the health system, such as consumption of medicines, plus the adversities of polymedication, as can be seen in Table 4.

Table 4:-Weekly consumption of medicines referred by the elderly

\begin{tabular}{|l|c|c|c|c|}
\hline & \multicolumn{2}{|c|}{ Yes } & \multicolumn{2}{c|}{ No } \\
\hline & $\mathbf{n}$ & $\mathbf{\%}$ & $\mathbf{n}$ & $\mathbf{\%}$ \\
\hline Medication for high cholesterol & 148 & 43,7 & 191 & 56,3 \\
\hline Medication for high blood pressure & 186 & 54,9 & 153 & 45,1 \\
\hline Medication for coronary or cerebrovascular diseases & 63 & 18,6 & 276 & 81,4 \\
\hline Medicationfor other heart diseases & 64 & 18,9 & 276 & 81,4 \\
\hline Medication for asthma & 18 & 5,3 & 321 & 94,7 \\
\hline Medication for diabetes & 89 & 26,3 & 250 & 73,7 \\
\hline Medicationfor joint pain or inflammation & 168 & 49,6 & 171 & 50,4 \\
\hline Medicationfor other pains (eg headache, back pain...) & 143 & 42,2 & 196 & 57,8 \\
\hline Medicationfor difficulty sleeping & 119 & 35,1 & 220 & 64,9 \\
\hline Medicationfor anxiety or depression & 61 & 18,0 & 278 & 82,0 \\
\hline Hormone medications for osteoporosis & 61 & 18,0 & 278 & 82,0 \\
\hline Medication for burning stomach sensation & 83 & 24,5 & 256 & 75,5 \\
\hline Medicationfor chronic bronchitis & 25 & 7,4 & 314 & 92,6 \\
\hline No medication & 43 & 12,7 & 296 & 87,3 \\
\hline
\end{tabular}

In our sample, only $12.7 \%$ of the population reported not taking any type of medication. It was verified, as in our study, that most consumed drugs are from the cardiovascular group, with greater consumption by women, and that the percentage of drugs in the cardiovascular group represents about $92.4 \%$ of the drugs consumed. Regarding medication consumption, 54.9\% reported taking medications for blood pressure control, $91.8 \%$ reported taking pain medication, of which $49.6 \%$ took medicine for osteoarticular pain, $43.7 \%$ take cholesterol medications and $35.1 \%$ report taking sleep-inducing medication.

Regarding medical treatment expenses, the study participants' responded according to what is presented in Table 5. Because this is self-reported and therefore potentially undervalued, it can be seen that $61.1 \%$ of the participants reported not having any financial burden, while $56.9 \%$ also stated that they did pay when they had specialty consultations requested by the family doctor. However, charges for specialty visits not required by the family doctor are assumed by $49.3 \%$ of the participants, a figure that increases to $65.2 \%$ when the elderly, in the exercise of their autonomy, resorts to medical care of their preference. Regarding dentistry consultations, $69.9 \%$ of the respondents paid the consultation in full. As for the payment of hospital admissions, it is verified that $48.1 \%$ reported not having any financial expenses with the hospitalization in public hospitals. In private hospitals, $42.8 \%$ reported paying in full.

Table 5:-Medical care expenses referred by the elderly

\begin{tabular}{|l|c|c|c|c|c|c|c|c|c|c|}
\hline & \multicolumn{2}{|c|}{ I pay in full } & \multicolumn{2}{|c|}{$\begin{array}{c}\text { I pay } \\
\text { almost } \\
\text { entirely }\end{array}$} & \multicolumn{2}{|c|}{$\begin{array}{l}\text { I pay less } \\
\text { than half }\end{array}$} & \multicolumn{2}{|c|}{$\begin{array}{c}\text { I do not } \\
\text { pay } \\
\text { anything }\end{array}$} & \multicolumn{2}{c|}{$\begin{array}{c}\text { Does not } \\
\text { know }\end{array}$} \\
\hline & $\mathbf{n}$ & $\mathbf{\%}$ & $\mathbf{n}$ & $\mathbf{\%}$ & $\mathbf{n}$ & $\mathbf{\%}$ & $\mathbf{n}$ & $\mathbf{\%}$ & $\mathbf{n}$ & $\%$ \\
\hline Pays for general practice consultation & 69 & 20,4 & 20 & 5,9 & 19 & 5,6 & 207 & 61,1 & 24 & 7,1 \\
\hline $\begin{array}{l}\text { Paysspecialty consultations requested } \\
\text { by family doctor }\end{array}$ & 65 & 19,2 & 27 & 8,0 & 21 & 6,2 & 193 & 56,9 & 33 & 9,7 \\
\hline $\begin{array}{l}\text { Paysspecialty consultations not } \\
\text { requested by family doctor }\end{array}$ & 167 & 49,3 & 25 & 7,4 & 20 & 5,9 & 65 & 19,2 & 62 & 18,3 \\
\hline $\begin{array}{l}\text { Pays for consultation with a doctor of } \\
\text { their choice }\end{array}$ & 221 & 65,2 & 20 & 5,9 & 18 & 5,3 & 29 & 8,6 & 51 & 15,0 \\
\hline Pays dentist & 237 & 69,9 & 19 & 5,6 & 8 & 2,4 & 19 & 5,6 & 56 & 16,5 \\
\hline
\end{tabular}




\begin{tabular}{|l|c|c|c|c|c|c|c|c|c|c|}
\hline Paysfor prescription drugs & 76 & 22,4 & 59 & 17,4 & 137 & 40,4 & 37 & 10,9 & 30 & 8,8 \\
\hline Payshospitalization in public hospitals & 53 & 15,6 & 27 & 8,0 & 18 & 5,3 & 163 & 48,1 & 78 & 23,0 \\
\hline Payshospitalization in private hospitals & 145 & 42,8 & 14 & 4,1 & 10 & 2,9 & 32 & 9,4 & 138 & 40,7 \\
\hline $\begin{array}{l}\text { Pays stays in nursing homes or home } \\
\text { nursing care, in case of chronic illness } \\
\text { or disability }\end{array}$ & 101 & 29,8 & 15 & 4,4 & 14 & 4,1 & 69 & 20,4 & 140 & 41,3 \\
\hline
\end{tabular}

In Table 6 we can observe the frequency of emotional problems referred by the elderly.

Table 6:-Frequency of emotional problems referred by the elderly

\begin{tabular}{|l|c|c|c|c|c|c|}
\hline & \multicolumn{2}{c|}{ Often } & \multicolumn{2}{c|}{ Sometimes } & \multicolumn{2}{c|}{ Seldom or never } \\
\hline & $\mathbf{n}$ & $\mathbf{\%}$ & $\mathbf{n}$ & $\mathbf{\%}$ & $\mathbf{n}$ & $\mathbf{\%}$ \\
\hline How often did they feel unaccompanied & 35 & 10,3 & 96 & 28,3 & 208 & 61,4 \\
\hline How often did they feel put aside & 20 & 5,9 & 75 & 22,1 & 244 & 72,0 \\
\hline How often did they feel isolated & 35 & 10,3 & 71 & 20,9 & 233 & 68,7 \\
\hline How often did they feel alone & 36 & 11,4 & 93 & 29,3 & 188 & 59,3 \\
\hline $\begin{array}{l}\text { How often did they have emotional problems } \\
\text { (depression or anxiety) that affected daily activities }\end{array}$ & 31 & 9,1 & 121 & 35,7 & 187 & 55,2 \\
\hline $\begin{array}{l}\text { How often did they have emotional problems } \\
\text { (depression or anxiety) that affected their relationship } \\
\text { with family and friends }\end{array}$ & 28 & 8,3 & 106 & 31,3 & 205 & 60,5 \\
\hline
\end{tabular}

As for how often they felt unaccompanied, put aside, isolated and alone, most reported "seldom or never", respectively, $61.4 \%, 72.0 \%, 68.7 \%$ and $59.3 \%$. However, it should be noted that $29.3 \%$ of the elderly have sometimes felt alone. Regarding the question "how often do you have emotional problems, including depression or anxiety, and which affected daily activities and relationships with family and friends" participants answered 55.2\% and $60.5 \%$ respectively, that seldom or never have been affected by emotional problems. We consider relevant, however, that $35.7 \%$ and $31.3 \%$ respectively, believe that emotional problems sometimes affect their relationship with daily activities and relationships with family and friends.

\section{Discussion of results:-}

From the analysis of the data we consider that the sociodemographic evaluation was in agreement with the expectations from the existing literature. According to the Census of 2011 (INE, 2012), Portugal has an accentuated demographic aging, with an elderly population (aged 65 and over) of $19.15 \%$, with a longevity index of 80.57 for women and 74.0 for men. INE (2012) also predicts that by 2050 this trend will be aggravated by a significant increase in this index, with a predicted value of 84.1 years in women and 77.9 years in men. Thus, the results found in elderly people living in rural parishes of the municipality of Vila Real reflect both national and international statistics. Eurostat (2013) also corroborates these statistics, predicting by 2060 an average life expectancy of 89 years for women and 84.9 years for men. This reality was also confirmed by Coelho Filho and Ramos (1999), stating that "the predominance of elderly women reflected the greater longevity of women in relation to men" (pp. 450-451).

Regarding marital status, the data found in this study is consistent with the statistics, since INE (2012) reports that $20 \%$ of the elderly live alone and $40 \%$ with other elderly people.

Within the level of education, the data found in our study is overlapping with the results obtained in a study carried out in a Portuguese community in 2001, where the author reports that the majority of the elderly (48.6\%) are illiterate (Menezes, 2001). Nunes (2009) also carried out a study according to which the elderly population had the first cycle of basic education (60\%), and Braga et al (2011) reached similar results.

The income obtained by the elderly is also paralleled in studies of various kinds, namely in Costa et al (2006), who found that $45.3 \%$ of the elderly received a monthly income equal to or less than the minimum wage, and that the majority $(89.5 \%)$ of the elderly had their own homes. 
Among the sociodemographic variables, low levels of schooling (87.0\%) and economic income $(90.9 \%$ live in retirement) are limiting the conditions for a full civic life, the basis of an ethics of relation that aims to promote values inherent to mankind in a global vision where the principles of autonomy, beneficence, non-malfeasance and justice should be enshrined. The world today lives on a double track. On the one hand, the increase of solidarity and the wonderful world of development. On the other, the world lives in the terrible world of introspective silence. Within these two differences there is a growth between two worlds where the level and conditions of life of the people are increasingly disparate, increasing social inequalities. It is a world to which the questions of bioethics really call attention because "man is primarily his life" (Entralgo, 2002).

The preservation of autonomy both physically and psychologically is one of the basic pillars of aging and should be reinforced and encouraged in the behavior of the elderly in order to promote the self-determination and dignity that gives responsibility and meaning to the ethical dimension of health.

The data obtained does not corroborate many of the studies carried out on the perception of health, namely that of Fransen et al. (2002) who argue that, with the increase in age, which results in greater attrition and prevalence of chronic diseases, the degree of dependence is increasing. However, in our study the perception of health status may be due to the size of the sample and to the fact that it is an elderly population that remains at home and, therefore, with levels of autonomy for daily activities which can lead to a better understanding of the quality of life (QoL), as it is also stated by the WHOQOL Group (1995), which affirms that "the individual perception of their position in life in the context of the culture and value system in which one lives and in relation to objects, expectations, standards and concerns of each individual. It is a broad concept of classification affected in a complex way by the physical health of the individual, social relations, level of independence and their relations with salient characteristics of their environment". However, most elderly patients reported osteoarticular pain, which is also corroborated in the study according to which the articular mobility of the elderly is diminished (Costa et al., 2006).

In a national study, Sousa et al. (2003) report that most respondents have a positive perception regarding their QoL and well-being, with $62.8 \%$ of the elderly being autonomous.

With the aging of the population, chronic diseases such as diabetes, cardiovascular and osteoarticular diseases predominate. In addition, neurological and mental problems, dental and bone diseases, as well as eye and hearing diseases, which greatly alter the perception of the QoL of the elderly, are still present. If it is true that the progress of medicine has allowed the increase of the average life and consequently the existence of a wide range of diseases, it is necessary to guarantee a positive attitude, not neglecting the gradual modifications which compromise the cultural understanding of old age, within the historical context of each individual.

Regarding the perception that the elderly have of their state of health, the values vary between 4 and 100 and the average is 61.63. Women have a worse perception of their health status (58.80) relative to men (65.97), taking into account a scale from 0 to 100, with 0 being the worst health condition and 100 the best perception of their health status. The information available in the National Health Survey 2005/2006 (INE, 2009) indicates that approximately $41.4 \%$ of the residents in mainland Portugal aged 65 and over consider their health status to be bad or very bad. This reality can also be found in a similar study by Araújo et al. (2011) on the perception of the health status of the population where it is stated that in rural areas the perception of QoL decreases the probability of individuals becoming aware of their weak state with continued practice of physical activity. The elderly, and in particular those who remain active and involved, are going through old age with a satisfactory life and therefore, in the light of the principle of equity, discriminatory and unfavorable attitudes should not be generated.

Although a large proportion of the elderly are in good health and there is some variability of opinion regarding the most prevalent changes in the elderly, it is observed that most of the problems identified are chronic and can persist for several years, causing QoL decrease and expenditures both in care and in health resources. Chronic disease, by itself, should not be a limiting factor, because when it comes to accompanying therapy (it does not treat diseases, it accompanies people), it allows the integral vision of the human person that accepting their limitations can enjoy the rights of any citizen, continuing to participate in a true citizenship.

When asked about the weekly consumption of drugs, we can observe that only $12.7 \%$ of the elderly did not take any type of medication and that the use of polymedication was prevalent. 
Studies have shown that the proportion of people with adverse reactions increases approximately $10 \%$ when the patient takes only one drug and almost $100 \%$ when ten medications are used (Katzung, 2006). The polypharmacy, usually used for polymedication, is a current practice in the elderly population and is explained by the number of chronic diseases and by the high incidence of symptoms and consultations in different specialties (Duarte and Diogo, 2005) and it carries multiple risks.

It is pertinent to use explicit methods, such as the Beers (2012) criteria, to avoid the use of potentially inappropriate medication and to ensure generalized measures of care and safety with pharmacological prescription in the elderly (Budinitz et al., 2007).

The proportion of elderly people in the population has increased exponentially, as previously noted, and thus, the rise in the prevalence of chronic diseases increases the rate of demand for health care as well as the frequent use of medicines. The most intensive use of health services reflects an increase in health care spending, which interferes with the family budget, especially of rural populations, as in the case of this study, where people are almost exclusively dependent on retirement pensions of less than 500 euro and on resources from subsistence agriculture. The knowledge of the reality about the direct costs with the disease situations will allow a better adaptation and rationalization of the resources in health. Moreover, the issue of the sharp increase in the price of medicines and the different medical acts, more than ever due to the budgetary restriction resulting from the memorandum of understanding with the tripartite commission (European Commission, European Central Bank, International Monetary Fund) obliges, according to Barros (2012), to reduce public spending on drugs by about one-third.The economistic perspective of health must not corrupt the holistic perspective nor the humanistic dimension of which it must cohere. However, the allocation of health resources to drug policy and the introduction of generics should take into account the economic power of the consumer. Since economics and ethics are complementary sciences, in which one defines the means and the other the ends, it must extract from the ethics the necessary guidelines so that its conclusions are visible in the process of therapeutic decision making.

Overall, the results show that the elderly have a reduced monetary contribution in medical treatments, which warrants caution in the interpretation, since they should not only be considered as an exercise of an autonomous and informed choice, if not by the limitation of the distributive justice of the financial resources, keeping in mind the level of instruction.

Campos (2001) states that the increase in life expectancy, accompanied by the epidemiological transition, implies the survival of more elderly people and the consequent increase in the expenses with the health of citizens. According to the author, all hypotheses point to the need to consider that people who are in the final segment of life are more likely to use health care and that increasing the density of the elderly in the general population will imply increases in expenditure. However, the author also notes that "it is not technically easy to identify health expenditures... which vary according to factors other than the determinants of the normal demand for health care" and that "it is in the inland communities, in small cities, towns and even in villages where elderly care runs better, where there is greater sensitivity from the community".

In the view of the National Ethics Council for Life Sciences (2012), "the debate on the cost of medicines and restrictions on prescription has recently intensified... making the need to propose a decision model based on the principle of justice that allows... the safeguarding of the dignity of those who are treated and of those who treat".

Regarding public health expenditure, Barros (2009) states that the price of most decisions regarding the use of medical and health care does not correspond to an illusory image that health is priceless. He says, for example, that "if we think of a trip to the dentist every month and that the price of the consultation tripled, it will be reasonable to predict that the user will change their behavior when searching for health care. At that time the user is only rediscovering the old notion that the demand for a good or service depends negatively on its price". He also states that "with health insurance, those who pay for the good or service might be a different entity from those who benefit from that good or service. Only this seemingly small difference will bring about a totally different result of resource allocation" and that, in our view, needs to be introduced in the public debate on the social state guided by the ethical principle of distributive justice.

It is essential to expand democratic practices in the field of health, and it is useful to make feasible strategies that seek to guarantee the participation of the subjects in the definition of their way of directing life and that they value in the daily life of so that the elderly can take their own health process, recognize it as a whole, and its emotional 
aspects. This is expressed in Table 6, where 31.3\% of respondents sometimes presented emotional problems which affected them in their relationships with family and friends (depression or anxiety).

In Portugal, 51\% of people over 64 live alone, particularly women and those with low educational level (Guerreiro, 2003). If living alone can be the result of individual paths, such as children leaving their parents' house or becoming a widow, rural areas also have a higher risk of poverty (Ministry of Labor and Social Solidarity, 2006) and loneliness because of desertification and loss of intergenerational ties. Of the changes observed in the behavior of the elderly, what is important to highlight is the alert about depressive behavior (Cohen and Eisdorfer, 1997). The elderly may be in a situation of continuous losses, such as the reduction of socio-family support, loss of occupational and economic status, continued physical decline and greater frequency of physical illnesses, which often causes feelings of discouragement and sadness that can generate depressive syndrome (Ballone, 2002). Different studies have shown that the highest prevalence of depression is seen in patients who have had strokes (25\% to $48 \%$ ) and coronary heart disease ( $8 \%$ to $44 \%$ ). In addition to the described diseases, emotional problems increase morbidity and mortality rates (Drago and Martins, 2012).

Depression, anxiety and frequent psychiatric disorders with serious consequences in the elderly are highlighted by the degree of incidence. Although the nature of this problem has changed at the beginning of this century, the WHO warned against the risks of these disorders and placed emphasis on pressure and anxiety in vulnerable populations such as the elderly (WHO, 2005).

In this study, there are no worrying values of loneliness and emotional problems, whose reasons may be related to the maintenance of an autonomous functional status that allows the accomplishment of daily life activities and the maintenance of intergenerational ties and the informal social network. However, given the demographic and social transitions that occur in the rural parishes of the municipality of Vila Real, the problems of loneliness and isolation of the elderly should continue to deserve a constant interest in the different social partners (municipalities, health and social sector institutions and public actors).

The reading of the expression of isolation and solitude of the elderly crosses with the structural changes of the families themselves, a result of the emigration of the children and, not infrequently, of the widows themselves and of relational losses, which compromise the social and intergenerational support and promote in their absence states of psychosocial morbidity. Therefore, the perceived quality of life is also the product of the human interactions that develop, so it is necessary to promote an intrinsic relationship between the operative situation, that is, the creation of social and human conditions that increase solidarity, decrease abandonment and combat desertification and bioethical reflection.

\section{Conclusion:-}

The mental representation of the individual condition and well-being is variable in time. Each person seeks the balance in each moment, according to the challenges that each situation puts them through, so that health is the reflection of a dynamic, continuous and integrative process, where all the social and health determinants contribute to the "construction" of the individual in his/her oneness. Taking into account the social determinants of health, this study points to four basic points in which policies can intervene: (i) reduce social stratification, i.e., reduce inequalities in terms of power, prestige, income and wealth that are linked to the socio-economic position occupied; (ii) reduce exposure to factors detrimental to health by groups in a less privileged position; (iii) seek to reduce the vulnerability of susceptible groups; (iv) by providing health care, reducing the unequal consequences of health problems, and preventing the socioeconomic deterioration of individuals who become ill.

In times of financial turmoil, such as those we experience today, there should be a policy that relates the financial impact of global health care delivery and of an eminently integrative nature of the different health management partners of the population, namely the populations themselves in their context, with the arguments of equity, social justice and human rights.

The importance of the narrative for the implementation of changes in health policies is considered fundamental, and it is necessary for public health scientists to stop believing that they can influence the way policies are formulated, simply by providing solid scientific evidence to the government. Strong evidence does not have the inherent power to bring about change if it is not presented in a persuasive and timely manner and if its relevance is not clear to policy makers, given the conjuncture. The use of narrative is no less ethical than the formulation of 
policies based on scientific evidence. In fact, narrative is the human vehicle through which the evidence reveals its full meaning (Gordis, 2004).

The allocation of economic resources is a fundamental element to enable better living conditions and health. However, there is evidence that countries with lower health resources have more satisfactory health indicators, so it is important to identify where and how resources should be distributed, taking into account the interventions outlined, with the aim of reducing inequities in health, i.e., the most sensitive points where such interventions can have greater impact.

We are pleased to note that the determinants of health arising from individual factors (genetic, biological and psychological) and from environmental, economic, social and cultural factors are now being implemented at a national and European level with networks and programs focused on specific environments.

The analysis of the determinants can contribute to the minimization of health inequalities, to subsidize the elaboration of policies and programs, considering that it is necessary to monitor the factors that positively or negatively condition the state of health, in order to enrich the already existing knowledge on the frequency and distribution of determinants in the population.

\section{Bibliographic References:-}

1. American Geriatrics Society (2012) Beers Criteria Update Expert Panel. American Geriatrics Society update Beers Criteria for potentially inappropriate medication use in alder adults. J Am Geriatr Soc.2012 Apr;60 (4): 616-31

2. Araújo, J., Ramos, E., \& Lopes, C. (2011). Estilos de vida e percepção do estado de saúde em idosos portugueses de zonas rural e urbana. Acta Médica Portuguesa, 24 (S2), 72-88.

3. Ballone, G.J. (2002). Depressão do idoso. In Psiquiatria geral. Retrieved from http://www.psiqweb.med.br/geriat/depidoso.html.Drago, S., \& Martins, R.M. (2012). A depressão no idoso. Millenium, 43, 79-94.

4. Banco Mundial (2009).Relatório sobre o desenvolvimento mundial: ageografia económica em transformação visão geral. Washington: Banco Internacional de Reconstrução.

5. Barros, P.P. (2009). Economia da saúde. Conceitos e comportamentos (2nd ed.). Coimbra: Almedina.

6. Barros, P.P. (2012). Restrição orçamental e problemas éticos na prescrição. In Fundamentos éticos nas prioridades em saúde, Actas do Ciclo de Conferências CNECV 2011. Lisboa: Ed. CNECV

7. Bonita, R., Irwin, A., \& Beaglehole, R. (2009). Promoting public health in the twenty-first century: The role of the World Health Organization. In I. Kawachi \& S. Wamala (Eds.), Globalization and health (Ch. 16, pp. 268284). New York: Oxford University Press.

8. Botelho, A. (2005). A funcionalidade dos idosos. In C. Paúl \& A.M. Fonseca (Coords.), Envelhecer em Portugal (pp. 115-135). Lisboa: Climepsi Editores.

9. Braga, M.C.P., Casella, M.A., Campos, M.L.N., \& Paiva, S.P. (2011). Qualidade de vida medida pelo WHOQOL-Bref: Estudo com idosos residentes em Juiz de Fora/MG. Revista APS, 14 (1), 93-100. Retrieved fromhttp://aps.ufjf.emnuvens.com.br/aps/article/view/965/450

10. Budnitz, D.S., Shehab, N., Kegler, S.R., \& Richards, C.L. (2007). Medication use leading to emergency department visits for adverse drug events in older adults. Arch Intern Med., 147 (11), 755-765. Retrieved from http://www.ncbi.nlm.nih.gov/pubmed/18056659

11. Campos, A.C. (2001). O envelhecimento da população e os gastos com a saúde. Revista Portuguesa de Saúde Pública, 19 (1), 25-27.

12. Coelho Filho, J.M., \& Ramos, L.R. (1999). Epidemiologia do envelhecimento no Nordeste Brasileiro: Resultados de inquérito domiciliar. Revista de Saúde Pública, 33 (5), 445-453. Retrieved fromhttp://www.scielo.br/pdf/rsp/v33n5/0629.pdf

13. Cohen, D., \& Eisdorfer, C. (1997). Depressão. In F.A.B. Calkins \& P.R. Katz, Geriatria prática (2a ed., pp. 301 311). Rio de Janeiro: Revinter.

14. Conselho Nacional de Ética para as Ciências da Vida. (2012). Parecer sobre um modelo de deliberação para financiamento do custo dos medicamentos. Lisboa

15. Costa, E.C., Nakatani, A.Y.K., \& Bachion, M.M. (2006). Capacidade de idosos da comunidade para desenvolver actividades de vida diária e actividades instrumentais de vida diária. Acta Paulista de Enfermagem, 19 (1.), Suppl 1, 43-48. Retirado de http://www.scielo.br/pdf/ape/ v19n1/a07v19n1.pdf

16. Direção Geral da Saúde. (2004a). Programa nacional para a saúde das pessoas idosas (Circular normativa $\mathrm{n}^{\circ}$ 13/DGCG). Lisboa 
17. Direção Geral da Saúde. (2004b). Programa nacional de intervenção integrada sobre determinantes da saúde relacionados com os estilos de vida (Despacho $\mathrm{n}^{\circ}$ 1916/2004 de 28 de janeiro). Lisboa.

18. Duarte, Y.A.O., \& Diogo, M.J.D. (2005). Atendimento domiciliário: Um enfoque gerontológico. São Paulo: Atheneu.

19. Entralgo, P.L. (2002). O que é o homem. Lisboa: Editorial Notícias.

20. Fransen, M., Woodward, M., Norton, R., Robinson, E., Butler, M., \& Campbell, A.J. (2002). Excess mortality or institutionalization after hip fracture: men are at greater risk than women. Journal of the American Geriatrics Society, 50 (4), 685-690. doi:10.1046/j.1532-5415.2002.50163.x

21. Geib, L.T. C. (2012). Determinantes sociais da saúde do idoso. Ciência\& saúde colectiva, 17 (1), 123-133.

22. Giraldes, M.R. (1996). Desigualdades socioeconómicas e seu impacte na saúde. Lisboa: Estampa.

23. Gordis, S. (2004). Epidemiology. Philadelphia: Elsevier Saunder.

24. Guerreiro, M. (2003). Pessoas sós: Múltiplas realidades. Sociologia, Problemas e Práticas, 43, p.31-49.

25. Guerreiro, M., Silva, A.P., Botelho, M.A., Leitão, A., Castro-Caldas, A., \& Garcia, C. (1994). Adapted to Portuguese population from a translation by Mini-Mental State Examination (MMSE). Revista Portuguesa de Neurologia, 1 (9), 9-10.

26. Instituto Nacional de Estatística. (2009). Anuário estatístico de Portugal 2008. Lisboa: Autor.

27. Katzung, B.G. (2006). Farmacologia básica e clínica (9a ed.). Rio de Janeiro: Guanabara Koogan.

28. Menezes, A.L.N.S. (2001). Perfil de saúde dos idosos de uma comunidade rural. Estudo do perfil de saúde dos idosos de uma comunidade rural - freguesia de Lamares, Concelho de Vila Real no ano de 2000. Dissertação para concurso de provas públicas não publicada, Vila Real, Escola Superior de enfermagem de Vila Real.

29. Nunes, C. (2009). O apoio social e a qualidade de vida dos idosos do Concelho de Faro. Dissertação de mestrado não publicada, Universidade do Algarve, Faro. Retrieved from https://sapientia.ualg.pt/bitstream/10400.1/564/1/Carla\%20\%20DISSERTA\%C3\%87\%C 3\%83O.pdf

30. Santana, P., \& Costa, C. (2012). A variação demográfica [Comunicação]. In X Curso Pós-Graduado sobre Envelhecimento, Coimbra, 21 de setembro.

31. Sousa, L., Galante, H., \& Figueiredo, D. (2003). Qualidade de vida e bem-estar dos idosos: Um estudo exploratório na população portuguesa. Revista de Saúde Pública, 37 (3), 364-371.

32. WHOQOL Group. (1995). World Health Organization Quality of Life Assessment (WHOQOL): Position paper from the World Health Organization. Social Science \& Medicine, 41 (10), 1403-1409. doi:10.1016/0277-9536 (95)00112-K

33. World Health Organization. (2005). Envelhecimento activo: Uma política de saúde. Brasília: Organização PanAmericana de Saúde. Retrieved from http://bvsms.saude.gov.br/bvs/ publicacoes/envelhecimento_ativo.pdf 